\title{
CONTROLE GENÉTICO DA ANTRACNOSE FOLIAR EM MILHO*
}

\author{
REGINA M.S. COÊLHO ${ }^{1}$, HERBERTE P. SILVA ${ }^{2}$, KÁTIA R. BRUNELLI ${ }^{3}$ \& LUIS E.A. CAMARGO ${ }^{3}$
}

'Centro Agropecuário de Gurupi, Universidade do Tocantins, Cx. Postal 66, CEP 77400-000, Gurupi, TO, fax (63) 312-3288,
e-mail: rmsartori@ hotmail.com; ${ }^{2}$ Empresa Brasileira de Sementes/Dow Agrosciences, Uberlândia, MG, e-mail:
herbertp@ terra.com.br; ${ }^{3}$ Departamento de Entomologia, Fitopatologia e Zoologia Agrícola, Escola Superior de Agricultura “Luiz
de Queiroz" - USP, Cx. Postal 09, CEP 13418-900, Piracicaba, SP, fax (19) 434-4839, e-mail: leacamar@ carpa.ciagri.usp.br

(Aceito para publicação em 27/06/2001)

Autor para correspondência: Luis Eduardo Aranha Camargo

COÊLHO, R.M.S, SILVA, H.P., BRUNELLI, K.R. \& CAMARGO, L.E.A. Controle monogênico da antracnose foliar em milho. Fitopatologia Brasileira 26:640-643. 2001.

\section{RESUMO}

Em experimento realizado em casa de vegetação com quatro linhagens e dois híbridos de milho (Zea mays), verificou-se variabilidade para resistência a queima foliar causada por Colletotrichum graminicola avaliada por meio das variáveis área total de lesão por planta (ATL), área média de lesão (AML), comprimento total de lesão por planta (CTL), comprimento médio de lesão (CML) e número de lesões por planta (NL). Quando dois isolados de C. graminicola foram inoculados nessas linhagens e em híbridos de milho não foi verificada interação diferencial entre isolados e genótipos do hospedeiro. Em estudos de herança da resistência, as linhagens genitoras L186 e L64 comportaram-se como suscetível e resistente, respectivamente, ao passo que o híbrido L186 x L64 apresentou resistência. A análise das frequiências observadas de plantas resistentes e suscetíveis na população $F_{2}$ resultantes da autofecundação do híbrido, indicou ocorrência de herança monogênica com dominância completa para o alelo que confere resistência à doença.

Palavras-chave: Zea mays, herança da resistência, raças fisiológicas, Colletotrichum graminicola

\section{ABSTRACT \\ Genetic control of corn leaf anthracnose}

Variability in resistance to corn (Zea mays) leaf anthracnose caused by Colletotrichum graminicola was detected among four lines and two hybrids for the variables: total area of lesion (ATL), average lesion area (AML), total lesion length (CTL), average lesion length (CML) and lesion number (NL). No differential interaction was detected among isolates of C. graminicola and inbred lines and hybrids. In studies about the mode of resistance to foliar anthracnose, the inbred lines L186 and L64 were susceptible and resistant, respectively, whereas the hybrid L184 x L64 were resistant. The observed frequency of susceptible and resistant $\mathrm{F}_{2}$ plants derived from selfing of $\mathrm{F} 1$ plants from the cross L186 x L64 indicated monogenic and dominant control of resistance

\section{INTRODUÇÃO}

Colletotrichum graminicola (Ces.) G.W. Wils. é agente causal de antracnose foliar e do colmo em milho (Zea mays L.). Recentemente a antracnose do colmo foi reconhecida como um dos principais problemas da cultura do milho em áreas que adotam o cultivo safrinha ou o sistema de plantio direto (Silva, 1997; Fancelli \& Dourado Neto, 2000). A doença ocorre em todas as principais regiões produtoras do Brasil, seja em plantios tardios ou em plantios efetuados em períodos normais (Fernandes e Balmer, 1990; Cruz et al., 1996). Segundo Bergstrom \& Nicholson (1999) lesões foliares podem servir como fonte de inóculo para

\footnotetext{
*Parte da Tese de Doutorado do primeiro autor apresentada à Escola Superior de Agricultura "Luiz de Queiroz" - USP (2000).

**Bolsista CNPq
}

infecções no colmo, que podem causar tombamento da planta e conseqüente redução na produtividade da ordem de $18 \%$ (Carson \& Hooker, 1981b) a 40\% (Smith, 1976; Perkins \& Hooker, 1979; White et al., 1979; Callaway et al., 1992). O emprego de genótipos resistentes é o método de controle mais eficaz tanto para a fase de podridão de colmo quanto para a fase foliar da doença

Na literatura são encontrados relatos do envolvimento de poucos genes na resistência do milho a este fungo. Silva (1983), por exemplo, estimou a ação de um a quatro genes controlando resistência à infecção no limbo foliar e um ou dois no caso de resistência à infecção na nervura central. Em ambos os casos, foram encontrados efeitos genéticos dominantes e aditivos. Badu-Apraku et al. (1987b) identificaram dois genes co-dominantes de resistência a antracnose foliar na fase de plântula e planta adulta em linhagens tropicais com base na análise de médias das 
gerações $\mathrm{F}_{1}, \mathrm{~F}_{2}$ e retrocruzamentos. Finalmente, Badu-Apraku et al (1987a) identificaram um gene de grande efeito controlando resistência à antracnose foliar. Outros trabalhos, embora não ofereçam estimativas do número de genes envolvidos, relataram efeitos genéticos dominantes para resistência (Lim \& White, 1978, Carson \& Hooker, 1981a).

O presente trabalho teve como objetivos: 1) verificar a patogenicidade de dois isolados de $C$. graminicola em quatro linhagens e dois híbridos de milho por meio de algumas variáveis de severidade e 2) estudar o modo de herança da resistência em uma população $F_{2}$ oriunda do cruzamento entre duas linhagens.

\section{MATERIAL E MÉTODOS}

O presente trabalho foi realizado no Departamento de Entomologia, Fitopatologia e Zoologia Agrícola da Escola Superior de Agricultura "Luiz de Queiroz" e no campo experimental da Empresa Brasileira de Sementes (EBS)/ Dow Agrosciences, em Cravinhos-SP.

\section{Obtenção dos isolados de Colletotrichum graminicola}

$\mathrm{O}$ isolamento de $C$. graminicola foi realizado a partir de acérvulos retirados de colmos de milho provenientes de campos de produção em Cravinhos-SP (isolado CRV) e em Cristalina - GO (isolado CRI). Para manutenção da patogenicidade, os isolados foram inoculados a cada dois meses em plântulas de milho com quatro a cinco folhas e reisolados após cada inoculação.

\section{Material Vegetal}

Foram utilizadas quatro linhagens de milho (L21, L22, L186 e L64), dois híbridos simples (L21 x L186 e L186 x L64) e indivíduos $\mathrm{F}_{2}$ resultantes da autofecundação de L186 x L64. As referidas linhagens e híbridos foram gentilmente cedidos pela EBS/Dow Agrosciences para a realização desse trabalho. Os indivíduos $\mathrm{F}_{2}$ foram obtidos na área experimental do Departamento de Entomologia, Fitopatologia e Zoologia Agrícola da ESALQ-USP. As linhagens L21 e L22 são linhagens de ciclo precoce de grãos duros alaranjados, oriundas de sintético constituído de linhas tropicais com predominância de germoplasma Suwan DMR. A linhagem L186 tem origem tropical, é de ciclo precoce e tem porte médio e grãos semiduros alaranjados. Foi extraída de uma população sintética constituída por linhagens oriundas de "Amarillo Dentado" e "flints" do Caribe. A linhagem L64 origina-se do mesmo sintético, é de ciclo precoce, porte baixo e possui grãos semiduros alaranjados.

\section{Patogenicidade de Colletotrichum graminicola}

Os isolados CRV e CRI foram inoculados nas linhagens L21, L22, L186 e L64 e nos híbridos L21 x L186 e L186 x L64 em um experimento conduzido em casa de vegetação. O ensaio seguiu um esquema fatorial 6 x 2 e um delineamento experimental em blocos ao acaso com três repetições. A parcela experimental foi constituída de um vaso contendo cinco plantas. As plantas foram mantidas em casa de vegetação a uma temperatura média de $30{ }^{\circ} \mathrm{C}$, sob alta umidade relativa do ar.

Para obtenção do inóculo, os isolados de $C$. graminicola foram cultivados em placas de Petri por um período de 20 dias em meio de aveia-ágar (40 g aveia, $17 \mathrm{~g}$ ágar, $1.000 \mathrm{ml}$ água), sob regime de alternância luminosa $\left(12 / 12\right.$ h) a $22{ }^{\circ} \mathrm{C}$. A suspensão do inóculo foi obtida pela adição de $20 \mathrm{ml}$ de água destilada a cada placa e raspagem da colônia com auxílio de espátula. A concentração da suspensão foi ajustada para 2,0 x $10^{5}$ conídios $/ \mathrm{ml}$. As inoculações foram feitas mediante pulverização das folhas em plantas com cinco-seis folhas. Vinte e quatro horas antes da inoculação e $24 \mathrm{~h}$ após a inoculação, as plantas foram acondicionadas em casa de vegetação sob condições de alta umidade relativa do ar. A avaliação da intensidade dos sintomas foi feita 14 dias após a inoculação. Para cada planta, os contornos das lesões de todas as folhas foram desenhados em uma superfície plástica transparente. $\mathrm{O}$ número de lesões por planta (NL) foi então determinado. Com auxílio de régua e papel milimetrado foram estimadas as variáveis: somatória do comprimento de todas as lesões (CTL), comprimento médio das lesões $(\mathrm{CML}=\mathrm{CTL} / \mathrm{NL})$, área total lesionada (ATL) e área média das lesões $(\mathrm{AML}=$ ATL/NL).

A análise de variância foi efetuada com o programa SAS 6.11.

\section{Herança da resistência em milho à antracnose foliar}

Plantas $\mathrm{F}_{2}$ obtidas da autofecundação do híbrido simples L186 x L64 foram utilizadas para estudar o controle genético da resistência à queima foliar neste cruzamento, em um experimento conduzido em casa de vegetação (1997) e outro em campo (safra 98/99). Plantas da geração $F_{1}$ e das linhagens genitoras foram incluídas nos ensaios como controles.

As plantas foram inoculadas por meio de suspensões conidiais obtidas de culturas puras do isolado CRI com 20 dias de idade em meio aveia-ágar (40 g de aveia, $17 \mathrm{~g}$ de ágar, $1000 \mathrm{ml}$ de água destilada), ajustadas à concentração de cerca de $2 \times 10^{5}$ esporos $/ \mathrm{ml}$. Em casa de vegetação, a inoculação foi realizada mediante pulverização das folhas em plantas de milho com 30 dias (cinco folhas). Esse experimento foi repetido três vezes, com 264, 308 e 248 plantas da geração $\mathrm{F}_{2}$ em cada repetição. Em condições de campo, na safra 1998/1999, foram realizadas inoculações aos 20, 27 e 34 dias após a emergência em 209 plantas da geração $\mathrm{F}_{2}$. $\mathrm{O}$ delineamento experimental utilizado foi o inteiramente casualizado. As plantas foram classificadas em resistentes ou susceptíveis de acordo com a ausência ou presença de qualquer sintoma característico, independente de sua intensidade. As freqüências observadas de plantas resistentes e susceptíveis, foram analisadas por meio do teste qui-quadrado para determinação do número de genes envolvidos e de seus efeitos gênicos. 


\section{RESULTADOS E DISCUSSÃO}

\section{Patogenicidade de Colletotrichum graminicola}

A análise da variância de valores transformados em $\log (\sqrt{ }(x+1))$ indicou ausência de diferença significativa entre os isolados para as diferentes variáveis. Entretanto, plantas inoculadas com o isolado CRI apresentaram sintomas da doença cerca de quatro dias mais cedo do que as plantas inoculadas com o isolado CRV (dados não apresentados). Este fenômeno pode estar relacionado ao maior período de incubação (cerca de dez dias) do isolado CRV verificado in vitro (Morello, 2000). Esta diferença no período latente, no entanto, pode resultar em diferenças significativas na quantidade de doença causada pelos isolados ao final de um ciclo da cultura, uma vez que um período latente menor possibilita maior número de ciclos do patógeno no transcorrer de uma epidemia. Assim, uma análise do comportamento dos dois isolados sob condição de epidemia pode revelar resultados diferentes dos aqui relatados. Também não foi verificada interação significativa entre genótipos dos hospedeiros e isolados do patógeno (dados não apresentados) para as variáveis avaliadas (NL, ATL, AML, CTL e CML), indicando a não distinção dos isolados em raças, considerando o material genético avaliado. Os resultados obtidos corroboram os verificados por Nicholson \& Warren (1981), Jenns et al. (1982), White et al. (1987) e Carson (1999), os quais também não constataram evidência da existência de raças de $C$. graminicola em milho.

A linhagem L64 e o híbrido L186 x L64 não apresentaram sintomas de queima foliar, mostrando-se altamente resistentes. Para as variáveis NL, AML e CML, a linhagem L186 foi mais suscetível que a linhagem L21. Considerando CTL, os materiais L186, L21 x L186, L22 e L21 foram semelhantes quanto à susceptibilidade. Entretanto, para a variável ATL, a linhagem L186 foi mais susceptível que as demais (Tabela 1). Observou-se alta correlação entre todas

TABELA 1 - Severidade média de antracnose foliar em genótipos de milho inoculados com dois isolados de Colletotrichum graminicola avaliada pelo comprimento e área total lesionada (CTL e ATL), comprimento e área média da lesão (CML e AML) e número de lesões (NL)

\begin{tabular}{|c|c|c|c|c|c|c|c|c|}
\hline TRATAMENTO & $\mathrm{CTL}_{1}$ & \multicolumn{2}{|c|}{$\operatorname{ATL}_{1}$} & \multicolumn{2}{|c|}{$\mathrm{CML}_{1}$} & \multicolumn{2}{|c|}{$\mathrm{AML}_{1}$} & $\mathrm{NL}_{1}$ \\
\hline L186 & 146,4 a & 406,2 & $\mathrm{a}$ & 36,3 & $\mathrm{a}$ & 83,0 & $\mathrm{a}$ & 34,9 a \\
\hline L21 X L 186 & $110,7 \mathrm{a}$ & 183,7 & $\mathrm{~b}$ & 25,5 & $a b$ & 48,7 & $a b$ & $26,0 \mathrm{ab}$ \\
\hline $\mathrm{L} 22$ & 78,6 a & 119,5 & $\mathrm{~b}$ & 16,3 & $a b$ & 33,5 & $a b$ & $17,4 a b$ \\
\hline $\mathrm{L} 21$ & 53,4 a & 71,1 & $\mathrm{~b}$ & 11,2 & $\mathrm{~b}$ & 20,3 & $\mathrm{~b}$ & $13,8 \quad b$ \\
\hline L64 & $\begin{array}{ll}0 & \mathrm{~b}\end{array}$ & 0 & $\mathrm{c}$ & 0 & $\mathrm{c}$ & 0 & c & 0 \\
\hline L 186 X L 64 & $\mathrm{~b}$ & 0 & $\mathrm{c}$ & 0 & $\mathrm{c}$ & 0 & $\mathrm{c}$ & 0 \\
\hline $\mathrm{DMS}^{2}$ & 0,557 & 0,560 & & 0,3 & & 0,7 & & 0,500 \\
\hline C.V. $(\%)^{2}$ & 21,06 & 19,31 & & 18,5 & & 19,3 & & 29,35 \\
\hline
\end{tabular}

${ }^{1}$ Médias (valores não transformados) na vertical seguidas de mesma letra não diferem entre si em nível de 5\% segundo teste de Tukey.

${ }^{2}$ Valores calculados para médias transformadas em $\log (\sqrt{ }(\mathrm{x}+1))$. variáveis testadas (Tabela 2), permitindo o mesmo agrupamento dos genótipos. Considerando que todas as variáveis foram eficientes em discriminar os genótipos quanto à resistência ao patógeno, sugere-se a utilização de escala diagramática baseada na área total lesionada para avaliação de sintomas, por ser um método rápido e direto comparado aos métodos de avaliação das outras variáveis.

\section{Herança da resistência em milho à antracnose foliar}

Uma vez que os dois isolados não diferiram em agressividade, optou-se pelo uso do isolado CRI devido a seu menor período de incubação in vitro. Nos três ensaios realizados em casa de vegetação e no ensaio de campo, a linhagem genitora L 186 comportou-se como susceptível, apresentando sintomas típicos da antracnose foliar, enquanto a linhagem L64 e o híbrido (L186 x L64) não apresentaram sintomas de queima foliar, demonstrando o mesmo comportamento observado no ensaio anterior. Tanto em casa de vegetação quanto em campo, cerca de 3/4 das plantas $\mathrm{F}_{2}$ apresentaram reação de resistência e 1/4 reação de susceptibilidade, caracterizado pela presença de lesões típicas da antracnose foliar. As frequiências observadas de plantas com e sem lesão não diferem daquelas esperadas no caso de herança monogênica com dominância completa para o alelo que confere resistência. Resultados semelhantes foram obtidos em condições de campo, onde a freqüência observada também correspondeu à esperada no caso de herança monogênica com dominância completa para o alelo que confere resistência (Tabela 3). O teste de heterogeneidade não foi significativo, indicando que houve homogeneidade entre os resultados obtidos nos diferentes experimentos (Tabela 3).

Este é o primeiro relato de resistência monogênica com dominância completa para o alelo que confere resistência em que o fenótipo resistente não apresenta sintomas de infecção do patógeno. No entanto, não há informações sobre a localização genômica dos mesmos. A localização e caracterização desse gene por meio de marcadores moleculares podem ser úteis a programas de melhoramento de milho por facilitar a sua introgressão em linhagens elites. Para futuras referências deste gene sugere-se adotar a denominação RCG1.

TABELA 2 - Correlações entre as variáveis de severidade de antracnose foliar, comprimento e área total lesionada (CTL e ATL), comprimento e área média da lesão (CML e AML) e número de lesões (NL) avaliadas aos 14 dias da inoculação

\begin{tabular}{|c|c|c|c|c|c|}
\hline Variável & CTL & ATL & CML & AML & $\mathrm{NL}$ \\
\hline CTL & & $0,94 *$ & $1,00 *$ & $0,98^{*}$ & $1,00 *$ \\
\hline ATL & & & $0,96^{*}$ & $0,99 *$ & $0,94 *$ \\
\hline CML & & & & $0,99 *$ & $1,00 *$ \\
\hline AML & & & & & $0,98^{*}$ \\
\hline $\mathrm{NL}$ & & & & & \\
\hline
\end{tabular}


TABELA 3 - Número de plantas de milho (Zea mays) $\mathbf{F}_{2}$ resistentes $(\mathrm{R})$ e suscetíveis $(\mathrm{S})$ à antracnose foliar avaliadas em três experimentos em casa de vegetação $(\mathrm{CV})$ e um experimento em campo

\begin{tabular}{|c|c|c|c|c|}
\hline Experimento & $\begin{array}{l}\text { Planta } \\
\text { resistente }\end{array}$ & $\begin{array}{c}\text { Planta } \\
\text { susceptível }\end{array}$ & $\chi^{2}$ & $\mathrm{p}<$ \\
\hline $\left.1 / \mathrm{CV}_{(\mathrm{D} . \mathrm{F} .}=1\right)$ & $\begin{array}{c}229 * \\
(228)^{*}\end{array}$ & $\begin{array}{c}75 \\
(76)\end{array}$ & 0,01 & 0,92 \\
\hline $\left.2 / \mathrm{CV}_{(\mathrm{D} . \mathrm{F} .}=1\right)$ & $\begin{array}{l}196 \\
(198)\end{array}$ & $\begin{array}{l}68 \\
(66)\end{array}$ & 0,04 & 0,84 \\
\hline $\left.3 / \mathrm{CV}_{(\mathrm{D} . \mathrm{F} .}=1\right)$ & $\begin{array}{l}188 \\
(186)\end{array}$ & $\begin{array}{l}60 \\
(62)\end{array}$ & 0,04 & 0,83 \\
\hline $4 / \mathrm{Campo}_{(\mathrm{D} . \mathrm{F} .=1)}$ & $\begin{array}{l}148 \\
(157)\end{array}$ & $\begin{array}{c}61 \\
(53)\end{array}$ & 0,82 & 0,36 \\
\hline Total $\chi_{(D, E,=4)}^{2}$ & & \multicolumn{3}{|c|}{0,91} \\
\hline$\chi^{2}$ (pool)(D.F. $\left.=1\right)$ & $\begin{array}{c}761 \\
(769) \\
\end{array}$ & $\begin{array}{c}264 \\
(257)\end{array}$ & \multicolumn{2}{|l|}{0,14} \\
\hline $\begin{array}{l}\text { Heterogeneidade } \\
\chi^{2} \text { (D.F.=5) }\end{array}$ & & & \multicolumn{2}{|c|}{$1,05^{\text {n.s. }}$} \\
\hline \multicolumn{5}{|c|}{$\begin{array}{l}\chi_{0,05 ; 1}^{2}=3,84 ; \chi_{0,05 ; 2}^{2}=5,99 ; \chi_{0,05 ; 5}^{2}=11,07 ; \\
{ }^{* 1} \text { freqüência observada; }{ }^{* 2} \text { frequiência esperada no caso de segregação } 3: 1 ;{ }^{\text {n.s. não }} \\
\text { significativo }\end{array}$} \\
\hline
\end{tabular}

\section{REFERÊNCIAS BIBLIOGRÁFICAS}

BADU-APRAKU, B., GRACEN, V.E. \& BERGSTROM, G.C. A major gene for resistance to anthracnose leaf bligth in maize. Plant Breeding 98:194-199. 1987a.

BADU-APRAKU, B., GRACEN, V.E. \& BERGSTROM, G.C. Inheritance of resistance to anthracnose stalk rot and leaf bligth in a maize inbred derived from a temperate by tropical germplasm combination. Maydica 32: 221-237. 1987b.

BERGSTROM, G.C. \& NICHOLSON, R.L. The biology of corn anthracnose: knowledge to exploit for improved management. Phytopathology 83: 596-608. 1999.

CALLAWAY, M.B., SMITH, M.E. \& COFFMAN, W.R. Effect of anthracnose stalk rot on grain yield and related traits of maize adapted to the northeastern United States. Canadian Journal Plant Science 72:1031-1036. 1992.

CARSON, M.L. Leaf bligth. In: White, D.G. (Ed.). Compendium of corn diseases. $3^{\text {rd }}$ ed. Saint Paul: American Phytopathological Society, 1999.

CARSON, M.L. \& HOOKER, A.L. Inheritance of resistance to stalk rot of corn caused by Colletotrichum graminicola. Phytopathology 71:1190-1196. 1981a.
CARSON, M.L. \& HOOKER, A.L. Inheritance of resistance to stalk rot of corn caused by Colletotrichum graminicola. Phytopathology 71:1190-1196. 1981b.

CRUZ, J.C., MONTEIRO, J.A., SANTANA, D.P., GARCIA, J.C., BAHIA, F.G.F.T.C., SANS, L.M.A. \& PEREIRA FILHO, I.A. Recomendações técnicas para o cultivo do milho. Brasília: Empresa Brasileira de Pesquisa Agropecuária - Serviço de produção de informação. 2a edição. 1996.

FERNANDES, F.T. \& BALMER, E. Situação das doenças de milho no Brasil. Informe Agropecuário 14:35-37. 1990.

JENNS, A.E., LEONARD, K.J. \& MOLL, R.H. Variation in the expression of specificity in two maize diseases. Euphytica 31:269-279. 1982.

LIM, S.M. \& WHITE, D.G. Estimates of heterosis and combining ability for resistance of maize to Colletotrichum graminicola. Phytopathology 68:13361342. 1978.

MORELLO, R.M.S.C. Resistência em milho (Zea mays L.) a Colletotrichum graminicola (Ces.) Wils. (Tese de Doutorado). Piracicaba. Escola Superior de Agricultura "Luiz de Queiroz". 2000.

NILCHOLSON, R.L. \& WARREN, H.L. Criteria for evaluation of resistance to maize anthracnose. Phytopathology 66: 86-90. 1981.

PERKINS, J.M. \& HOOKER, A.L. Effects of anthracnose stalk rot on corn yields in Illinois. Plant Disease Reporter 63:26-30. 1979.

SILVA, H.P. Herança da resistência à antracnose foliar em milho (Zea mays L.) e métodos de avaliação (Dissertação de Mestrado). Piracicaba. Escola Superior de Agricultura "Luiz de Queiroz". 1983.

SMITH, D.R. Yield reduction in dent corn caused by Colletotrichum graminicola. Plant Disease Reporter 60:967-970. 1976.

WHITE, D.G., YANNEY, J. \& ANDERSON, B. Variation in pathogenicity, virulence, and aggressiveness of Colletotrichum graminicola on corn. Phytopathology 77:999-1001. 1987.

WHITE, D.G., YANNEY, J. \& NATTI, T.A. Anthracnose stalk rot. Proceedings, Thirty-fourth annual corn and sorghum research conference, American Seed Trade Association. 1979. pp. 1-15. 